\title{
The Art of Managing the Spine Diseases in Indonesia: Is it A Well-Developing Health System in a Developing Country?
}

\author{
Rully Hanafi Dahlan ${ }^{1 *}$, Neni Sri Imaniyati ${ }^{1}$, Faiz Mufidi $\mathbf{M}^{1}$, Nandang Sambas ${ }^{1}$, Sevline Estethia Ompusunggu ${ }^{2}$ \\ and Farid Yudoyono ${ }^{2}$
}

${ }^{1}$ Pasca Sarjana Universitas Islam Bandung, Indonesia

${ }^{2}$ Department Neurosurgery, Padjadjaran University, Indonesia

Submission:November 08, 2017; Published: January 10, 2018

*Corresponding author: Rully Hanafi Dahlan, Doctoral Studies Program of Legal Science, Pasca Sarjana Universitas Islam Bandung, Indonesia, Email: rullybill@gmail.com

\section{Abstract}

When we are talking about health, this is mean that we are discussing a never ending topics. In this world, health is a priority on the international agenda. New international initiatives such as The Global Fund for AIDS, TB and Malaria, the 3 by 5 Initiative (to provide access to antiretroviral therapy to 3 million people living with HIV/AIDS in developing countries by the end of 2005), and the Global Alliance on Vaccines and Immunization, are increasing the funding available at country level to expand disease control efforts [1]. Recently, focus on clearer identification of the beneficiaries of health problem and programmes is highlighting the extent to which they have failed the poorest populations, and stimulating a new focus on strategies to reach vulnerable groups [2]. The key questions concern how best to approach strengthening [3], and what specific types of action are appropriate to specific types of setting. Much is known about the barriers or constraints to greatly increasing ('scaling up') health services [4]. However, remarkably little is known about best how to relax these constraints, whether through reformed service delivery strategies, or different human resource management policies, or new organizational structures [5]. The 1990s witnessed widespread efforts in health sector reform across the world. Although progress was made in some countries towards improved performance, the reforms highlighted the need for better information and evidence to guide reforms. Our concern is how knowledge of health systems can be increased and applied to improve the health of the worst-off of the world's population, in this case, Indonesian population. We use the term 'health system' to include all levels, from service delivery to policy making and of course, implementation.

Keywords: Spine diseases; Developing country; Health system

\section{The Health System}

The Health system cannot divide as a small piece or part, but it's a whole idea of one integrated system. Its included all the organizations, institutions and resources, that are devoted to producing health actions whose primary intent it's to improve health result. There were four vital functions of health system, and defined as:

A. Service Provision: Both formal and informal service providers, public or private, at any level from rural area to urban area, all level of services.

B. Resource generations: all of inputs like human resources, physical capital, medical instrument or devices, drug and medical things.

C. Financing: Value and source of money resources is very important for the health system, more over the cash flow stability. Need coordination together with pooling resources and the mechanism of transferring to service providers.

D. Stewardship: Role of oversight of the health system, included government policy, future vision, direction, collecting the problem and data [6].

Without a health system that can use money well, spending will not merely be inefficient. It may be useless, or conceivably counterproductive [7]. A plumbing system analogy was used, that water cannot be provided to a building simply by filling storage tanks. There must be pipes through which the water can flow and these must not be too narrow, or clogged, or full of holes; there must be valves that direct it to where it is needed and the system of pipes and valves must extend throughout the building. In reality, constraints to using additional funds effectively exist at all levels of the health system. 


\section{Open Access Journal of Neurology \& Neurosurgery}

\section{The Health Research System}

In human kind, any part of the worlds, research is always needed to make an improvement. Without research, there will be no improvement. Research will act as data collector, analizator, at the same time as evaluator and planner for the future direction [8]. Health research is a driving force for improving the performance of health systems and the health of individuals and populations. However, it is often a fragmented, competitive and highly specialized activity, with researchers in different disciplines often working in isolation. Moreover, the overall emphasis of research priorities, viewed internationally, is heavily skewed by the bias of the funding available in each country. In recent years, some progress has been made in efforts to shift priorities. For example, new research funding has been made available to tackle problems such as the absence of vaccines for key causes of mortality such as malaria and HIV/AIDS, the scarcity of effective drugs for malaria and TB, and the lack of adequate diagnostic tests. Initiatives to support researcher interaction include the Multilateral Initiative on Malaria (MIM) which is bringing African malaria researchers of all disciplines together and supporting information exchange and capacity development. The health research system can be seen as one of the subsystems of the broader health system [9].

\section{Health System Research}

Health systems research can be defined as 'the production of knowledge and applications to improve how societies organize themselves to achieve health goals, including how they plan, manage and finance activities to improve health, as well as the roles, perspectives and interests of different actors in this effort. Health systems research includes research on health policies, though this is sometimes separately distinguished, as in the phrase health policy and systems research. It also includes health services research, which could be seen as a subset of health systems research, focusing on service delivery [10]. Health system research has many benefit, including find what makes health system doesn't work well. From many source, this paper showed the problem might happened in developing country [11], such Indonesia, as:

A. Maternal and child health problem: Maternal mortality, neonatal, perinatal mortality, infant mortality.

B. Family planning and nutritional problem: Utilization of child spacing services, malnutrition.

C. Infectious disease control: Malaria, dengue, TB patients, oral health.

D. Chronic disease founding and managing: TB patients, Tumor patients.

E. Primary health care, water and sanitation: drug provision and use, functioning of primary health care, coverage and use of sanitation.
F. AIDS/ Sexually transmitted disease: condom use, information, education, communication, good knowledge, attitudes, practices, incidence of gonorrhea.

G. Management and quality of health care services: staff attrition, staff education and training, patient overcrowding, collection of primary health care data, referral procedures, perceived quality of care [12].

\section{Research : The State of the Art in Selected Area and Selected Case}

It is not easy to organize an overview or even a plan, of the state of the art of health system in low and middle-income countries, because there were very few studies. Epidemiologists, public health specialists and economists dominated the field. The situation has changed a lot, as policy-makers, researchers and other stakeholders have become aware of the seriousness and complexity of the problems that health systems face. The field is now very broad and changing rapidly. This growing diversity is predicated on an awareness that countries, and regions within countries, differ greatly in their economic and institutional arrangements and, consequently, the performance of their health systems and the issues to which health systems research can contribute. There is no consensus on how to classify countries in terms of health system development and relevant contextual factors. One approach is to classify in terms of per capita GDP and region, although this approach does not capture factors that influence health system performance such as human resources, institutional arrangements and governance. Some author prefers three categories of countries identified.

Health system research first developed in advanced market economies, which have highly structured health systems, created in a contextconducive to the functioning of complex arrangements. This context includes economic stability, a relatively slow pace of social change, efficient tax and social security systems, a wellorganized legal and regulatory framework and enough trained people to operate these institutions. Some low and many middleincome countries also have stable and complex arrangements that include relatively strong government administration and professional regulation. They tend to have well-established public health services. Research findings in the advanced market economies are most relevant to these countries. All countries in this as categorized one. Second categorized countries are some of countries have weak government administrative systems and professional regulatory arrangements. This type of country can be found in all regions. A typical country of this type frequently has very low income and might have more severe challenges, such as prolonged economic crisis and/or the epidemic of HIV/AIDS. Government administrations that were weak during the post-colonial period have been weakened further as a result of financial problems, political crises, conflict and institutional decay. Meanwhile, community-level arrangements to help households cope with shocks have been stretched to breaking point, putting further pressure on health services. 
Donor initiatives are an important aspect of the institutional environment within which these health systems operate.

A final category of countries are experiencing rapid economic and institutional change associated with transition to a market economy. Their health systems have had to adapt to radical changes in their economic environment and confront an ideological shift involving increased doubts about the role of the state. The experience of these countries is uncovering important lessons about the influence of rules-based legal and administrative arrangements and of public understanding and expectations of the performance of health systems.

\section{Referral System : Levels of Health Care}

\section{Four levels of health providers defined:}

Level 1 of health care were: Primary Health Care Clinic (PHCC), Community Health Care Centre (CHCC) and District Hospital (DH). Each of providers has differences in structure and human resources, but they categorized as the first level. PHCC is the first step in the provision of health care and offers services such as immunization, family planning, anti-natal care and treatment of common disease, treatment and management of tuberculosis, HIV/AIDS counseling among other services, include social education. If the clinic cannot solve the problem and assists, they will refer the patient to CHCC. CHCC is the second step in the provision of health care but can also be used for first contact care. A Community health care centre offers similar services to PHCC with the addition of 24 hours maternity service, emergency care and casualty and a short stay ward. The CHCC will refer a patient to DH when necessary. This is the third step in the provision of health care. These District Hospitals (DH) will normally receive referral from and provide generalist support to community health centers and clinics such as diagnostic, treatment, care, counseling and rehabilitation services. Clinical services include Surgery, Obstetrics \& Gynecology, Out-Patients Department, Medicine, Pediatrics, Mental Health, Geriatrics, Casualty and Clinical Forensic Medical Services among other services. These hospitals receive referrals from the Community Health Centers and Clinics. Most care will be delivered by doctors and primary health care nurses. If the District Hospital cannot help a patient they will be referred to the local Regional Hospital for treatment.

Level 2, this is the second level of health care: These hospitals will normally receive referral from and provide specialist support to a number of district hospitals. If the Regional Hospital (RH) cannot help they will refer to the Provincial Tertiary Hospital.

Level 3, these hospitals, called Provincial Tertiary Hospital (PTH): will receive referral from and provide subspecialist support to a number of regional hospitals and is the third level of health care. These hospitals are staffed by specialists and generalists and offer services such as neurosurgery, neurology, Plastic \& reconstructive surgery,
Cardiology, Urology, Pediatric surgery, maxillio-facial surgery, Psychiatry, Occupational health and Orthopedics amongst other services. If a Provincial Tertiary Hospital cannot help they will refer to a National Central Hospital.

Level 4, called Central Hospital (CH): Are the fourth and highest level of health care. These hospitals will consist of very highly specialized referral units which together provide an environment for multi-speciality clinical services, innovation and research. People are referred to these hospitals by Provincial Tertiary Hospitals. To manage very advance case, in this level also there a hospital call specialized hospital (SZH), these hospitals will provide care only for certain specialized groups of patients. They will include chronic psychiatric and TB hospitals, as well as specialized spinal injury and acute infectious disease hospitals. Central hospital sometimes called as national hospital (NH).

\section{Spine Hospital}

Spine hospital is categorized as sub specialized hospital, therefore is a level 4 referral system. In Indonesia, most specialized case still taken care in level 3, and sometimes level 2. Improvement of this referral system is very important to achieve maximal outcome of the patient. Mistake in any part of the referral system, will give very bad result to the patient. This paper is made to discuss some problem that occurred generally in referral system, especially in selected area, which is our centre, and selected cases, spine cases. Data was collected for the last 6 years experienced.

\section{Background}

Most spine patient come to our centre with many problem, which resulting as bad outcome and high morbidity and castatrophic. The lack of knowledge about health problem is one of the major problem in developing countries. This condition leads to poor judgment of symptoms and delayed of diagnosis. The needs of advanced diagnostic tools, surgery and medical treatments in spinal pathologies compound those difficulties in achieving the optimal outcome. But all the problems were not well-documented as an objective data to evaluate the adequacy of the health system.

\section{Objective}

Learn the system, discuss the problem, and try to make an overview about each phase, such as; the pre-hospitalization, during hospitalization, surgery and post- hospitalization problems in a single centre study, in Bandung city, West Java Province.

\section{Methods}

This is the retrospective study with statistical analysis. We reviewed the records of patients who presented to Neurospine unit of Neurospine Perihperal Nerve and Pain Division, Neurosurgery Departments Hasan Sadikin General Teaching Hospital, Bandung from 2010 through 2016. 


\section{Open Access Journal of Neurology \& Neurosurgery}

\section{Results}

There were 590 consecutive patients included in the study who met the inclusion criteria. The data was recorded for the demographics, time of the initial symptoms to diagnosis, surgical procedure, pathology entities, and 12-months follow- up obedience. We described the complicating factors from patient's history taking and literature review.

\section{Conclusion}

The good collaboration of the surgeons, medical caregivers, peers and relatives support plays important role to establish the proper data registry that can enhance the development of health system in our centre.

\section{Referances}

1. Macroeconomics and Health: Investing in health for economic development: Report of the Commission on Macroeconomics and Health. World Health Organization, Geneva, Switzerland.

2. (2003) Poverty and health. DAC guidelines and reference series. Paris, $\mathrm{OECD} / \mathrm{WHO}$.

3. (2003) Shaping the future. World Health Report 2003. World Health Organization, Geneva, Switzerland.

4. (2004)The Millennium Development Goals for Health. Rising to the challenges. World Bank, Washington DC, USA.
5. Mills A, Hanson K (2003) Special issue: expanding access to health Interventions in low and middle income countries: constraints and opportunities for scaling-up. Journal of International Development 15 (1): 1-131.

6. (2000) Health systems: Improving performance. The World Health Report 2000. World Health Organization, Geneva, Switzerland.

7. (2002) Improving health outcomes of the poor. Report of Working Group 5 of the Commission on Macroeconomics and Health. World Health Organization, Geneva, Switzerland.

8. Sadana R, Pang T (2003) Health research systems: a framework for the future. Bull World Health Organ 81(3): 159.

9. (1999) The $10 / 90$ report on health research. Geneva, Global Forum for Health Research, Geneva, Switzerland.

10. (2000) Health research for development: the continuing challenge. Bangkok, 10-13 October 2000. International Conference on Health Research for Development, Bangkok.

11. Baris E (1998) Defining and delimiting the boundaries of the Alliance for Health Systems and Policy Research. Geneva, Background document, Alliance for Health Policy and Systems Research, Geneva, Switzerland.

12. (1996) Investing in health and development. Report of the ad hoc committee on health research relating to future intervention options, Geneva, World Health Organization, Geneva, Switzerland.

\section{Your next submission with Juniper Publishers} will reach you the below assets

- Quality Editorial service

- Swift Peer Review

- Reprints availability

- E-prints Service

- Manuscript Podcast for convenient understanding

- Global attainment for your research

- Manuscript accessibility in different formats ( Pdf, E-pub, Full Text, Audio)

- Unceasing customer service

Track the below URL for one-step submission https://juniperpublishers.com/online-submission.php 